\title{
Hormone therapy after risk-reducing surgery in patients with BRCA1/BRCA2 mutation: evaluation of potential benefits and safety
}

\author{
(D)Agaldo Lopes da Silva Filho' \\ (D) Gabriella Martins Carvalho ${ }^{2}$ \\ (iD) Larissa Cristelli de Sena² \\ Lívia Passini Guimarães Gomes² \\ (iD) Marcos Flávio Habib Valério ${ }^{2}$ \\ (iD) Raíssa Isabelle Leão Martins ${ }^{3}$ \\ (iD) Eduardo Batista Cândido ${ }^{4}$
}

\begin{abstract}
1. Professor Titular do Departamento de Ginecologia e Obstetrícia da UFMG, Belo Horizonte, MG, Brasil. 2. Acadêmico da Faculdade de Medicina da UFMG, Belo Horizonte, MG, Brasil. 3. Médica Residente em Ginecologia e Obstetrícia do Hospital das Clínicas da UFMG, Belo Horizonte, MG, Brasil. 4. Professor Adjunto do Departamento de Ginecologia e Obstetrícia da Faculdade de Medicina da UFMG, Belo Horizonte, MG, Brasil.
\end{abstract}

http://dx.doi.org/10.1590/1806-9282.66.8.1134

\section{SUMMARY}

Women with mutations in the BRCA 1 and 2 genes are at increased risk for ovarian and breast cancer and therefore candidates for risk-reducing surgery, including salpingo-oophorectomy and mastectomy. Risk-reducing salpingo-oophorectomy (RRSO) is considered the most effective prophylactic measure for ovarian cancer prevention in this group of patients. This procedure involves loss of ovarian function and induced menopause. Estrogen therapy is the most effective treatment for controlling vasomotor symptoms and improving the quality of life of climacteric women. However, the potential hormonal stimulation of these tumors and the risk of breast cancer are a concern regarding the safety of hormone replacement therapy (HRT) in this population. This article aims to review the current evidence regarding the potential benefits and safety of HRT after RRSO.

KEYWORDS: Mutation. Estrogen replacement therapy. Salpingostomy. Ovariectomy. Salpingo-oophorectomy. Breast neoplasms. Ovarian neoplasms.

\section{INTRODUCTION}

Epithelial ovarian cancer is responsible for approximately 125,000 deaths annually worldwide, ${ }^{1}$ with a higher incidence in more developed countries. In Brasil, it is estimated there are 6,150 new cases and 3,879 deaths due to ovarian cancer every year. ${ }^{2}$ Approximately $70 \%$ of women with ovarian cancer are diagnosed with metastatic or locally advanced disease (stages III and IV), with approximately $30 \%$ of five-year survival. Despite the high rates of response to chemotherapy initially, approximately $80 \%$ of the women with advanced disease present recurrence within two years after the initial treatment. ${ }^{3,4}$

Among the most important risk factors for the development of ovarian cancer is a family history 
of breast or ovarian cancer, particularly in women with two or more first-degree relatives affected by it. ${ }^{5}$ Mutations in the DNA repair pathways, as well as in the genes of susceptibility to breast cancer 1 and 2 (BRCA 1 and 2), predispose to an increased risk of breast and ovarian cancer. Women with mutations in these genes have an increased risk of developing ovarian cancer (15-56\%) and breast cancer (45-80\%) throughout life when compared to the general population (ovarian cancer, $1.4 \%$; breast cancer, $12 \%$ ). ${ }^{6}$ However, some evidence suggests that the risk of developing ovarian cancer is different in those with BRCA1 mutations (45-60\%) and BRCA2 mutations $(11-35 \%)^{6}$

\section{Risk-reducing salpingo-oophorectomy (RRSO)}

RRSO provides patients with BRCA mutations a significant reduction in the risk of ovarian cancer, i.e., approximately $80 \%$, and of breast cancer, i.e., approximately $50 \%,{ }^{6,7}$ in addition to a reduction in mortality. ${ }^{8}$ Considering the substantial difference in the phenotypes of breast and ovarian cancers associated with BRCA mutations, further studies are necessary to determine separately the risk reduction in patients with BRCA1 and BRCA2 mutations. The indication for this procedure should take into account various factors, such as patient age, current, and desired parity, and the current risk of malignancy development. ${ }^{6}$ It is recommended to perform RRSO in women with mutations in BRCA1 between the ages of 35-40 years and, for those with BRCA2 mutations, between 40-45 years. ${ }^{6}$

The risk for breast and ovarian cancer in patients with BRCA1 mutations begins to increase around 30-40 years, while in patients with BRCA2 mutations, it increases approximately ten years later, allowing for a postponement of surgery in the latter. ${ }^{6,8}$ However, delaying RRSO should be avoided to prevent reducing its protective effect against breast cancer, so it should be indicated for women aged 35-40 years with defined offspring or earlier when there is a family history of early-onset cancer. ${ }^{6}$

\section{Induced menopause}

Induced menopause is the term recommended by North American Menopause Society (NAMS) to define the cessation of menstruation after bilateral oophorectomy or iatrogenic ovarian ablation after chemotherapy or radiotherapy. ${ }^{9}$ The symptoms of induced menopause are usually more intense than those associated with natural menopause due to the sudden onset of symptoms, younger age, and their effects on physical and psychological problems characteristic of cancer therapy, such as concerns with body image and sexual dysfunction. ${ }^{10}$ In these patients, induced menopause can lead to adverse health outcomes, including cardiovascular diseases, osteoporosis, and cognitive impairment. Estrogen deficiency can also result in vasomotor symptoms such as vaginal dryness, fatigue, and mood and sleep changes, adversely affecting the quality of life. ${ }^{10,11}$

Thus, the management of the climacteric symptoms is essential to optimize the quality of life of patients. Estrogen replacement therapy is considered the most effective treatment for vasomotor symptoms, in addition to providing benefits regarding osteoporosis and cardiovascular disease. ${ }^{12}$ However, the potential hormonal stimulation of these tumors and the risk of breast cancer pose a concern regarding the safety of hormone therapy (HRT) in this population. The decision to indicate or contraindicate HRT for patients with mutations in the genes BRCA 1 and 2 after RRSO should be based on the best available evidence. $^{10}$

\section{Impacts of hormone replacement therapy}

If there is no contraindication due to cardiovascular risk, the first choice of treatment for vasomotor

FIGURE 1. BENEFITS OF HORMONE REPLACEMENT THERAPY (HRT) AFTER RISK-REDUCING SURGERY IN PATIENTS WITH BRCA1/BRCA2 MUTATIONS.

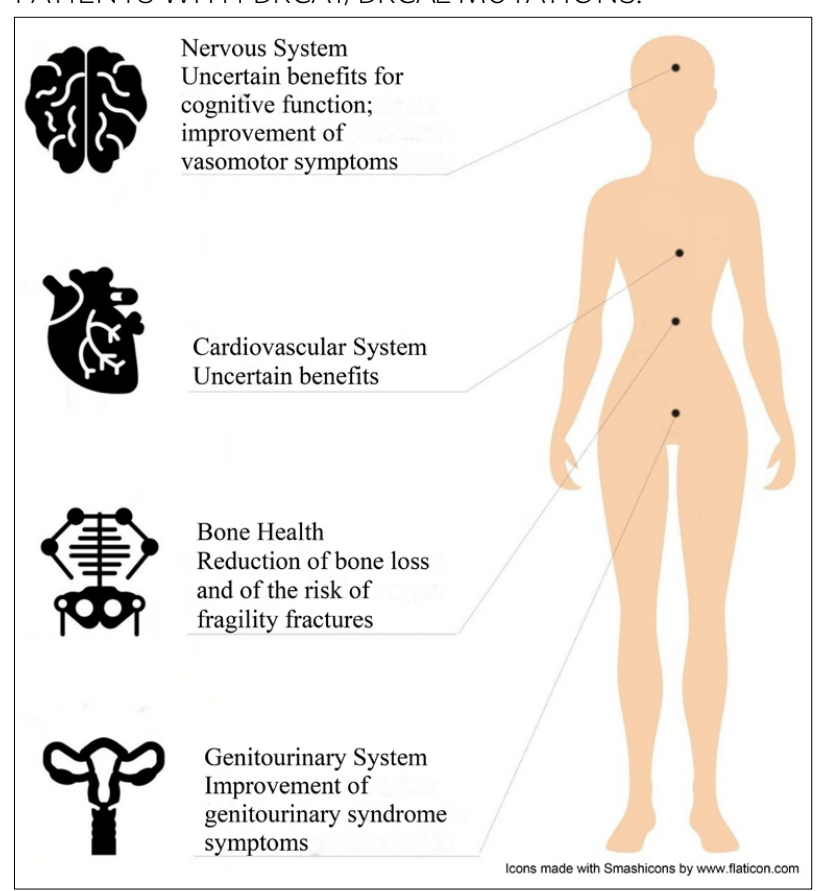


symptoms is systemic estrogen replacement therapy. In patients with hormone receptor-negative tumors submitted to hysterectomy, it is recommended to use the lowest dose of estrogen for the minimum possible time. If the uterus was preserved, it is necessary to associate progestogen. ${ }^{12}$

\section{Genitourinary and vasomotor symptoms and quality of life}

Vasomotor symptoms are usually characterized by a sudden onset of heat sensation in the upper chest and face, which can become widespread. It usually lasts between 2 and 4 minutes and may be associated with profuse sweating, palpitation, and anxiety. ${ }^{13}$ The combination of vulvovaginal atrophy and urinary tract dysfunction constitutes the "genitourinary syndrome of menopause". ${ }^{13}$ This is clinically manifested as vaginal dryness, dyspareunia, dysuria, bladder hyperactivity, and recurrent urinary infections.

Estrogen replacement is the most effective treatment for controlling vasomotor symptoms and improving the quality of life of symptomatic women. ${ }^{13}$ It is also associated with an improvement of symptoms of vulvovaginal atrophy, bladder hyperactivity, and recurrent urinary tract infections. ${ }^{13}$ Studies show there are benefits from HRT to the quality of life of women with BRCA mutations who undergo risk-reducing salpingo-oophorectomy, with a reduction of vasomotor symptoms and improvement of sexual function. ${ }^{8}$

\section{Bone health}

The decline in the levels of estradiol after menopause increases bone resorption, contributing to fractures. ${ }^{13}$ In this perspective, estrogen replacement reduces the bone loss associated with menopause and, consequently, the risk of fractures due to fragility. ${ }^{13}$ In the case of women who underwent RRSO, the use of HRT also decreases the likelihood of bone disease. ${ }^{8}$

\section{Cardiovascular health and cognitive function}

During the reproductive period, women have a lower incidence of cardiovascular diseases in comparison with men, but this difference no longer exists after menopause due to the loss of the protective effect of estrogen on the lipid profile. However, there is not enough evidence to recommend the use of HRT for primary or secondary prevention of cardiovascular diseases. Even so, it is important to highlight that HRT can be linked to the reduction of cardiovascular risk in women who underwent RRSO in pre-menopause. ${ }^{8}$

The existence of benefits from HRT on the cognitive function of women after menopause is still uncertain $^{13}$. Specific studies on the impact of HRT on cardiovascular health and cognitive function in women with BRCA mutations are scarce. ${ }^{8}$

\section{Risk of breast cancer}

Several studies have shown an increased risk of breast cancer with HRT after menopause, particularly with the combined replacement of estrogen and progesterone. ${ }^{8,13}$ These findings led to a great concern regarding hormone replacement in women who already have an increased risk of developing the disease, such as carriers of BRCA mutations.

However, based on studies carried out in this specific population, the reduction of breast cancer risk with pre-menopause RRSO in women with BRCA mutations and no personal history of breast neoplasias is not affected by the use of HRT. ${ }^{8}$

Among these studies, there is a meta-analysis conducted by Marchetti et al. ${ }^{14}$ based on three cohorts (Kotsopoulos et al. ${ }^{17}$; Gabriel et al. ${ }^{18}$; Rebbeck et al. ${ }^{19}$ ), which together included 1,100 women with BRCA1 and BRCA2 mutations who underwent RRSO. It was concluded that HRT did not significantly affect the risk of breast cancer in this population, both when considering all cohorts $(\mathrm{RR}=1.01 ; 95 \% \mathrm{CI}=0.16-1.54)$ or only the prospective cohorts $(\mathrm{RR}=0.98 ; 95 \% \mathrm{CI}=$ 0.63-1.52).

In addition, the analysis of a subgroup of women based on the formulation of the HRT used demonstrated that estrogen alone presented a lower risk for breast cancer in comparison to combined HRT. In total, among users of HRT, 326 used estrogen replacement alone and 114 used a combination of estrogen and progesterone and found no significant difference regarding the risk of breast cancer when comparing both groups. However, the risk of breast cancer risk was lower for women who used estrogen alone, both in the study population as a whole $(\mathrm{OR}=0.62 ; 95 \% \mathrm{CI}$ $=0.29-1.31)$ and in that included only in prospective studies $(\mathrm{OR}=0.53 ; 95 \% \mathrm{CI}=0.25-1.15) .{ }^{14}$

In this perspective, the systematic review carried out by Gordhandas et al. ${ }^{8}$ based on 100 papers with the keywords "hormone replacement therapy", "BRCA" and "risk reduction" came to similar conclusions both on the absence of significant differences in the risk of breast cancer with the use of hormone replacement 
therapy in women carriers of BRCA mutations and regarding the possible superiority of the use of estrogen alone in this population.

It is also important to highlight that the breast cancer in women with BRCA1 mutations usually has a triple-negative phenotype, i.e., hormone receptor-negative, while women with BRCA2 mutations generally present neoplasms with the expression of estrogen and progesterone receptors. So, is it possible that hormone replacement therapy impacts the risk of breast cancer differently in these two groups of patients. ${ }^{8}$ In this context, it is necessary to observe that most patients in the studies mentioned above include BRCA1 mutations and that usually there are scarce data on the use of hormone replacement therapy in patients with BRCA2 mutations. Therefore, although HRT seems a plausible option for managing the symptoms of menopause, the data available on its safety must be analyzed with caution in the context of women with BRCA2 mutations. ${ }^{14}$

\section{Other prophylactic surgeries \\ Hysterectomy}

Prophylactic hysterectomy for patients with BRCA mutations is not recommended as routine. ${ }^{15}$ However, estrogen replacement alone is associated with increased risk of endometrial cancer and RRSO without concomitant hysterectomy increases the risk of this cancer being of the serous type and histologically more aggressive. ${ }^{14}$

Some evidence suggests that the hysterectomy concomitant to RRSO could be considered for the following reasons: theoretical risk of cancer of the remnant uterine tube; reducing the risk of endometrial pathology in women with breast cancer prior to RRSO who are on tamoxifen, and simplification of a possible HRT, making it possible to use estrogen alone, which does not alter the risk of breast cancer ${ }^{6}$.

\section{Salpingectomy}

Recent data indicate the distal portion of the uterine tube as the place of origin of most serous ovarian cancers of high degree. This etiopathogenic hypothesis increases the possibility of two-step surgery for patients with BRCA1/2 mutations: a pre-menopausal risk-reducing salpingectomy and a late oophorectomy ${ }^{11,16}$. However, there are still important questions on the effectiveness, potential impact on ovarian function, and most appropriate allocation of this strategy in medium- and high-risk women ${ }^{16}$.
Non-hormonal alternatives for the relief of symptoms

As illustrated in Table 3, among the non-hormonal medications that have demonstrated effectiveness in controlling vasomotor symptoms are paroxetine (7.5 $\mathrm{mg} /$ day), venlafaxine ( $75 \mathrm{mg} /$ day $)$, and gabapentin (900-1.200 mg/day). For the management of genitourinary syndrome symptoms, topical estrogen therapy may be the most appropriate, particularly in cases of moderate or severe symptoms that did not improve with the use of vaginal moisturizers. ${ }^{12}$

TABLE 3. NON-HORMONAL OPTIONS FOR THE GENITOURINARY SYNDROME OF MENOPAUSE.

\begin{tabular}{l|l|l} 
Preparation & Composition & \multicolumn{1}{l}{ Effects } \\
\hline $\begin{array}{l}\text { Vaginal } \\
\text { moisturizers }\end{array}$ & $\begin{array}{l}\text { Preparations } \\
\text { based on } \\
\text { polycarbophil, } \\
\text { hyaluronic acid, } \\
\text { polyacrylic acid, } \\
\text { or pectin. } .^{\mathbf{3}}\end{array}$ & $\begin{array}{l}\text { When used regularly (at least twice } \\
\text { a week) can provide an effective } \\
\text { non-hormonal approach for the } \\
\text { relief of symptoms of vaginal } \\
\text { atrophy. Although useful, these are } \\
\text { probably inferior to therapy with } \\
\text { estrogen. In addition, they did not } \\
\text { provide any reduction in the symp- } \\
\text { toms of the lower urinary tract or } \\
\text { asymptomatic bacteriuria. }\end{array}$ \\
\hline $\begin{array}{l}\text { Vaginal } \\
\text { lubricants }\end{array}$ & $\begin{array}{l}\text { Various presen- } \\
\text { tations, usually } \\
\text { water- or sili- } \\
\text { cone-based. }\end{array}$ & $\begin{array}{l}\text { They are used to temporarily allevi- } \\
\text { ate (during sexual activity) dryness } \\
\text { and dyspareunia. They do not } \\
\text { revert changes caused by vaginal } \\
\text { atrophy. }{ }^{\mathbf{1 3}}\end{array}$ \\
\hline
\end{tabular}

\section{FINAL CONSIDERATIONS}

Women with mutations in the genes BRCA1 and BRCA2 have an increased risk of developing ovarian and breast cancer throughout life compared to the general population. The most effective strategy for reducing this risk is RRSO. However, induced menopause is one of its consequences, which generates negative impacts, affecting the quality of life and longevity. HRT is the only measure capable of significantly compensating hormonal deprivation and neutralizing the symptoms of menopause.

Although evidence suggests that HRT does not decrease the protective effect of RRSO in patients with mutations, the security concerns regarding estrogen and progesterone intake reduce their use in this scenario. There are also data demonstrating that the use of estrogen alone after RRSO does not increase the risk of breast cancer among women with BRCA1 mutations. The effects of progestogen hormone replacement therapy in patients with mutations, however, require further studies. 


\section{RESUMO}

Mulheres portadoras de mutações nos genes BRCA 1 e 2 possuem risco aumentado para cânceres de ovário e mama e, portanto, são candidatas às cirurgias redutoras de risco, incluindo a salpingo-ooforectomia e a mastectomia. A salpingo-ooforectomia redutora de risco (SORR) é considerada a medida profilática mais efetiva para prevenção do câncer de ovário nesse grupo de pacientes. Esse procedimento implica a perda da função ovariana e menopausa induzida. A estrogenioterapia é o tratamento mais efetivo para o controle de sintomas vasomotores e melhora da qualidade de vida de mulheres no climatério. No entanto, a potencial estimulação hormonal desses tumores e o risco de câncer de mama constituem uma preocupação com a segurança da terapia hormonal (TH) nesta população. Este artigo tem como objetivo uma revisão das evidências atuais quanto aos benefícios potenciais e segurança da TH após SORR.

PALAVRAS-CHAVE: Mutação. Terapia de reposição de estrogênios. Salpingostomia. Ovariectomia. Salpingo-ooforectomia. Neoplasias da mama. Neoplasias ovarianas.

\section{REFERENCES}

1. United States. National Cancer Institute. Cancer stat facts: ovarian cancer Bethesda: National Cancer Institute; 2019. [cited 2019 Nov 11]. Available from: https://seer.cancer.gov/statfacts/html/ovary.html

2. Brasil. Instituto Nacional do Câncer. Câncer de ovário. Rio de Janeiro: Instituto Nacional do Câncer; 2018. [cited 2019 Nov 11]. Available from: https:// www.inca.gov.br/tipos-de-cancer/cancer-de-ovario

3. Kurman R/, Shih leM. Molecular pathogenesis and extraovarian origin of epithelial ovarian cancer: shifting the paradigm. Hum Pathol. 2011;42(7):918-31.

4. Nash MA, Ferrandina G, Gordinier M, Loercher A, Freedman RS. The role of cytokines in both the normal and malignant ovary. Endocr Relat Cancer. 1999;6(1):93-107.

5. La Vecchia C. Ovarian cancer: epidemiology and risk factors. Eur J Cancer Prev. 2017;26(1):55-62.

6. Marchetti C, ladarola R, Palaia I, di Donato V, Perniola G, Muzii L, et al. Hormone therapy in oophorectomized BRCA1/2 mutation carriers. Menopause. 2014;21(7):763-8.

7. Rebbeck TR, Levin AM, Eisen A, Snyder C, Watson P, Cannon-Albright L, et al. Breast cancer risk after bilateral prophylactic oophorectomy in BRCA1 mutation carriers. J Natl Cancer Inst. 1999;91(17):1475-9.

8. Gordhandas S, Norquist BM, Pennington KP, Yung RL, Laya MB, Swisher EM. Hormone replacement therapy after risk reducing sal pingo-oophorectomy in patients with BRCA1 or BRCA2 mutations; a systematic review of risks and benefits. Gynecol Oncol. 2019;153(1):192-200.

9. Shifren LL, Gass ML; NAMS Recommendations for Clinical Care of Midlife Women Working Group. The North American Menopause Society recommendations for clinical care of midlife women. Menopause. 2014;21(10):1038-62.

10. Hinds L, Price J. Menopause, hormone replacement and gynaecological cancers. Menopause Int. 2010;16(2):89-93.

11. Blok F, Dasgupta S, Dinjens WNM, Roes EM, van Beekhuizen HI, Ewing-Graham PC. Retrospective study of a 16 year cohort of BRCA1 and BRCA2 carriers presenting for RRSO: prevalence of invasive and in-situ carcinoma, with follow-up. Gynecol Oncol. 2019;153(2):326-34.
12. Del Carmen MG, Rice LW. Management of menopausal symptoms in women with gynecologic cancers. Gynecol Oncol. 2017;146(2):427-35.

13. Stuenkel CA, Davis SR, Gompel A, Lumsden MA, Murad MH, Pinkerton $\mathrm{V}$, et al. Treatment of symptoms of the menopause: an endocrine society clinical practice guideline. J Clin Endocrinol Metab. 2015;100(11):3975-4011.

14. Marchetti C, De Felice F, Boccia S, Sassu C, Di Donato V, Perniola G, et al. Hormone replacement therapy after prophylactic risk-reducing salpingo-oophorectomy and breast cancer risk in BRCA1 and BRCA2 mutation carriers: a meta-analysis. Crit Rev Oncol Hematol. 2018;132:111-5.

15. Goldman ME. Life after treatment: quality-of-life concerns in patients treated for cancer. J Natl Compr Canc Netw. 2017;15(5S):744-7.

16. Long Roche KC, Abu-Rustum NR, Nourmoussavi M, Zivanovic O. Risk-reducing salpingectomy: Let us be opportunistic. Cancer. 2017;123(10):1714-20.

17. Kotsopoulos I, Gronwald I, Karlan BY, Huzarski T, Tung N, Moller P, et al; Hereditary Breast Cancer Clinical Study Group. Hormone replacement therapy after oophorectomy and breast cancer risk among BRCA1 mutation carriers. JAMA Oncol. 2018;4(8):1059-65.

18. Gabriel CA, Tigges-Cardwell |, Stopfer |, Erlichman |, Nathanson K, Domchek SM. Use of total abdominal hysterectomy and hormone replacement therapy in BRCA1 and BRCA2 mutation carriers undergoing risk-reducing salpingo-oophorectomy. Fam Cancer. 2009;8(1):23-8.

19. Rebbeck TR, Friebel T, Wagner T, Lynch HT, Garber JE, Daly MB, et al; PROSE Study Group. Effect of short-term hormone replacement therapy on breast cancer risk reduction after bilateral prophylactic oophorectomy in BRCA1 and BRCA2 mutation carriers: the PROSE Study Group. I Clin Oncol. 2005;23(31):7804-10.

20. O'Donnell RL, Clement KM, Edmondson RJ. Hormone replacement therapy after treatment for a gynaecological malignancy. Curr Opin Obstet Gynecol. 2016:28(1):32-41.

21. Whicker M, Black J, Altwerger G, Menderes G, Feinberg J, Ratner E. Management of sexuality, intimacy, and menopause symptoms in patients with ovarian cancer. Am J Obstet Gynecol. 2017;217(4):395-403. 